\title{
Population biology of Porites astreoides and Diploria strigosa on a shallow Caribbean reef
}

\author{
Peter J. Edmunds* \\ Department of Biology, California State University, 18111 Nordhoff Street, Northridge, California 91330-8303, USA
}

\begin{abstract}
The detrimental impacts of anthropogenic disturbances on tropical coral reefs have been studied in detail, but there have been limited efforts to determine which corals might endure these adverse conditions. This study focused on 2 Caribbean corals that have survived better than most in recent years on shallow reefs (5 to $9 \mathrm{~m}$ depth) in St. John, US Virgin Islands, and it used demographic models to explore their responses to disturbance. The species studied were Porites astreoides, which has weedy life-history characteristics, and Diploria strigosa, which is relatively non-weedy and in this location appears robust against environmental assaults. Populations were censused on varying schedules from 1994 to 2007, and a tag-and-resurvey procedure for individual colonies was repeated annually between 1999 and 2007 (P. astreoides) or 2002 and 2007 (D. strigosa). The results were used to parameterize size-based matrix models (size classes: I, $\leq 40 \mathrm{~mm}$; II, 41 to $80 \mathrm{~mm}$; and III, $\geq 81 \mathrm{~mm}$ diameter), and bootstrap resampling was used to attach confidence intervals to population parameters and projections. In contrast to the declining population of the historically dominant coral Montastraea annularis in St. John, the intrinsic rate of population increase $(\lambda)$ rose gradually for $P$. astreoides between 1999 and 2007. For $D$. strigosa, while $\lambda$ behaved somewhat erratically from 2002 to 2007, the overall trend was also upward. For both species, $\lambda$ was $>1$ at the end of the study, showing that the populations were growing. Over the next $100 \mathrm{yr}$, projections suggest that $P$. astreoides and $D$. strigosa will increase in abundance, even when impacted by recurrent disturbances, variable recruitment, and varied success of the largest colonies; size-frequency distributions demonstrated that their populations will remain dominated by medium ( $>23$ and $>25 \%$, respectively) and large ( $>20$ and $24 \%$, respectively) colonies, regardless of the conditions investigated. The success of $P$. astreoides and D. strigosa in St. John is strongly related to the dynamics of the largest colonies - notably their low mortality and high chance of remaining in the largest size class - and these characteristics favor sustained population growth in an era when many corals are declining in abundance. $P$. astreoides and $D$. strigosa now appear poised to experience a period of enhanced abundance on reefs in at least one Caribbean location.
\end{abstract}

KEY WORDS: Demography $\cdot$ Coral $\cdot$ Scleractinian $\cdot$ Caribbean $\cdot$ Population

\section{INTRODUCTION}

Understanding the factors causing changes in population size has been an important objective of biology for centuries (Malthus 1798), as has forecasting how populations will change in the future (Cole 1954). Historically, ecological forecasting has focused on organisms with special significance, such as species that are commercially important (Serchuk et al. 1980) or endangered (Fujiwara \& Caswell 2001), but much of the contemporary interest in this topic has been driven by the influences of anthropogenic disturbances (Clark et al. 2001), particularly those attributed to global climate change (GCC) (IPCC 2007). It is likely that such forecasts will reveal population declines for many species (Parmesan 2006), which therefore could be described as 'losers' in an era of GCC, but population stasis or increases for other species (Parmesan 2006), which therefore could be described as 'winners' (Loya et al. 2001). 
Over the last $20 \mathrm{yr}$, coral reefs have become one of the conspicuous ecosystems in which the effects of GCC are acute (Lesser 2007), and the prognosis for their future is poor (Knowlton 2001). The threats posed to coral reefs by GCC are serious because of the vulnerability of their scleractinian architects to the main manifestation of climate change (i.e. rising temperature and declining seawater $\mathrm{pH}$, Hoegh-Guldberg et al. 2007), and because the effects of GCC have been superimposed on those of other anthropogenic disturbances that have impacted reefs for decades (Brown 1997). The ecological implications of decades of coral reef degradation are serious (Knowlton \& Jackson 2008), but against the backdrop of globally declining coral cover (Gardner et al. 2003, Bruno \& Selig 2007), it is important to consider the possibility that coral communities might change rather than disappear entirely (Hughes et al. 2003, Mydlarz et al. 2010). This possibility is cause for guarded optimism, although whether this outcome is feasible will be determined by the ultimate severity of ocean acidification, and whether the reduction in $\mathrm{pH}$ will prevent the Scleractinia from persisting as a calcifying taxon (Hoegh-Guldberg et al. 2007).

In the case of regionally elevated seawater temperatures that became prominent in the 1980s (Glynn 1993), and the extensive coral mortality that high temperature can cause through bleaching (Fitt et al. 2001), there has been considerable debate (e.g. Sampayo et al. 2008) regarding the proposed adaptive value of such events (Buddemeier \& Fautin 1993). However, since the adaptive bleaching hypothesis was published (Buddemeier \& Fautin 1993), the scientific landscape of coral biology has changed as the taxonomic diversity of the Symbiodinium symbionts has been unveiled (Stat et al. 2006), and potentially beneficial shuffling of Symbiodinium genotypes within corals has been detected (Jones et al. 2008). Perhaps it is these kinds of effects, together with the classic life-history attributes of weedy taxa (Grime 1977), that have allowed some corals, such as Porites astreoides in the Caribbean, to increase in relative abundance while other corals have undergone declines in population size (Green et al. 2008).

The objective of this study was to evaluate how coral populations on shallow Caribbean reefs might change in coming decades. Using the fringing reefs of St. John, US Virgin Islands, as an experimental system, I use empirical data from as early as 1994 to complete demographic analyses of 2 scleractinian corals, Porites astreoides and Diploria strigosa, that are characteristic of these habitats and, over the last $23 \mathrm{yr}$, appear to have enjoyed relative ecological success while other corals have survived poorly e.g. Acropora spp. (Aronson \& Precht 2001) and Montastraea annularis (Ed- munds \& Elahi 2007). Having constructed demographic models, I use the results to project the populations $100 \mathrm{yr}$ into the future. The notion that $P$. astreoides and $D$. strigosa have recently enjoyed relative ecological success was motivated by $23 \mathrm{yr}$ of annual time-series analyses of coral community structure in St. John (Edmunds 2002), which suggested that colonies of these species recruited, grew, and survived better than other corals, and that the sizes of their populations remained stable or increased (Green et al. 2008, P. J. Edmunds unpubl. data). As these events unfolded, the shallow coral reefs in St. John changed significantly (Edmunds 2000, Rogers \& Miller 2006, Rogers et al. 2008), with one reef losing $82 \%$ of its coral cover by 2009 (Edmunds \& Elahi 2007, P. J. Edmunds unpubl. data), and throughout the Caribbean coral cover declining an average of $62 \%$ from 1987 to 2001 (Gardner et al. 2003). Stable or increasing population trajectories for any coral species on contemporary coral reefs is notable, and for $P$. astreoides and $D$. strigosa these trajectories suggest that these species may be poised to experience a period of enhanced abundance on the shallow reefs of St. John, and at least for P. astreoides, perhaps elsewhere in the Caribbean (Green et al. 2008).

\section{MATERIALS AND METHODS}

Study sites and general approach. Fringing reefs occur in shallow water $(<9 \mathrm{~m}$ deep) along the south shore of St. John, where much of the substratum is igneous rock and $\leq 8 \%$ is typically occupied by scleractinian corals. To enumerate the population dynamics of Porites astreoides (yellow morph, Gleason 1993) and Diploria strigosa, census data from 1994 and annually thereafter were used to quantify the density of juvenile colonies, defined as colonies $\leq 40 \mathrm{~mm}$ diameter (Bak \& Engel 1979, Edmunds 2000, 2004). In addition, more detailed demographic analyses were initiated in 1999 with a description of the population structure at fixed intervals ( 3 to 5 yr), and a tagging program that was designed to quantify the fate of colonies at yearly intervals. The fate of colonies was used to parameterize size-based matrix models as used first for corals by Hughes (1984) and later by others (Done 1988, Andres \& Rodenhouse 1993, Fong \& Glynn 2000, Hughes \& Tanner 2000, Lirman 2003, Edmunds \& Elahi 2007 , Santangelo et al. 2007).

Density of juvenile corals as an estimate of recruitment. Recruitment of Porites astreoides and Diploria strigosa was estimated from the density of juvenile colonies ( $\leq 40 \mathrm{~mm}$ diameter) of Porites spp. and Diploria spp., which have been measured since 1994 at up to 6 permanent sites (one at $9 \mathrm{~m}$ and five at $5 \mathrm{~m}$ depth) 
between Cabritte Horn and White Point (Fig. S1 in the supplement, available at www.int-res.com/articles/ suppl/m418p087_supp.pdf). This approach provides a compromise among the advantages of exploiting legacy data, the reality of identifying small corals, and the biological goal of enumerating actual recruits (i.e. the smallest corals that can be detected on the benthos), but it had several limitations.

First, the genus-level analysis was necessitated by the difficulty of identifying corals to species when they occurred as a few polyps or a colony several millimeters in diameter, but it overestimated the density of juvenile $P$. astreoides and $D$. strigosa because of congeners (i.e. P. porites, P. furcata, D. clivosa, and D. labrynthiformis). In some cases, most frequently for larger colonies in the juvenile size class, it was possible to identify juveniles to species, and these analyses suggested that $P$. astreoides (yellow morph) accounted for $\geq 66 \%$ of juvenile Porites spp., and D. strigosa for $\geq 47 \%$ of juvenile Diploria spp. It was not possible to retrospectively sub-sample the counts of juvenile colonies from 1994 to 2007 for cases of certain species identification, as such identifications were distributed haphazardly through the surveys and their selection would have excluded unique legacy data describing the density of juvenile corals over $14 \mathrm{yr}$.

Second, the density of juvenile corals underestimates actual recruitment by the unknown, but likely large, proportion that dies in the first 6 mo of benthic existence (Dunstan \& Johnson 1998, Vermeij \& Sandin 2008), or succumbs to high mortality within the juvenile size class (Edmunds \& Gates 2004). Although recruitment (sensu stricto) has rarely been reported for Porites astreoides or Diploria strigosa, results from 5 to $7 \mathrm{~m}$ depth in Bermuda suggests recruitment could be as high as $377 \mathrm{~m}^{-2}$ over $4 \mathrm{mo}$ for $P$. astreoides, and for Diploria spp. (results were not separated by species) as high as $1.9 \mathrm{~m}^{-2}$ over 12 mo (Smith 1992). Finally, estimates of recruitment from annual surveys of densities of juvenile colonies are upwardly biased by the subset of juveniles that recruit prior to the census year (i.e. they are $>1$ yr old) (Edmunds 2007).

Unfortunately, the magnitude (and sometimes opposing directions) of the biases introduced by the aforementioned limitations is unknown for St. John, and potentially could remain intractable to quantification for years. Critically, counts of coral recruits to species are required on natural surfaces, and while fluorescence census techniques at night offer potential to enumerate such corals (Baird et al. 2006), species-level analyses are still impossible. Comparison of the density of juvenile corals on natural surfaces and the density of coral recruits on adjacent settlement tiles offers one means to better understand the relationship between these 2 life stages, and such studies are under- way in St. John. However, in the absence of explicit measures of the density of recruiting or juvenile Porites astreoides or Diploria strigosa, the population projections described in this study are completed using densities of juvenile Porites spp. and Diploria spp. Projecting the population structures under differing recruitment regimes revealed some of the implications of the biases inherent in this approach.

To census juvenile corals, surveys were completed at up to 6 sites that included 3 used for the demographic analysis of Porites astreoides (Yawzi Point, Cabritte Horn, and Tektite) as well as 2 used for the demographic analysis of Diploria strigosa (Yawzi Point and Tektite). Together these sites provided a representative sample of the shallow fringing reefs at 5 to $9 \mathrm{~m}$ depth. Juveniles were identified to genus and counted in quadrats $(0.5 \times 0.5 \mathrm{~m}, \mathrm{n}=40$ at each site $)$ located randomly each year along one $40 \mathrm{~m}$ transect at each site (Edmunds 2000). Five sites were censused in 1994, and these same sites were censused from 1996 to 1998 (n = 200 quadrats); limited funding restricted analysis to only 2 of these sites in 1995 ( $\mathrm{n}=80$ quadrats), but in 1996 additional funding led to the inclusion of an additional site (Cabritte Horn), and thereafter, this site and the original 5 were censused (from 1999 to 2007, n = 238 to 240 quadrats).

Demographic analyses. The demographic analyses for Porites astreoides were completed at Yawzi Point, Cabritte Horn and Tektite, and for Diploria strigosa, at Yawzi Point and Tektite. The population structure was quantified as the number of colonies in discrete size classes for a known area of reef (i.e. to define the population vector), and these data for 2007 were used to initiate $100 \mathrm{yr}$ population projections.

To quantify population structure, quadrats (either $1 \times$ $1 \mathrm{~m}$ or $5 \times 2 \mathrm{~m}$ ) were placed randomly along transects at a constant depth, and the number and sizes of Porites astreoides and Diploria strigosa colonies were recorded. At least two $50 \mathrm{~m}$ transects were censused at each site surveyed. Surveys were completed in selected years spaced throughout the study in order to capture the changes in population structure that are expressed over longer periods (i.e. $>1 \mathrm{yr}$ ); more frequent analyses of population structure were limited by logistical constraints. Colony sizes were measured as the average of the major and minor diameters of the basal portion of the living tissue. For P. astreoides, the population structure was quantified in 1999, 2003, and 2007, and pooled among sites each year to describe the population structure. The population structure for $D$. strigosa was quantified in 2003 at Yawzi Point and Tektite, and in 2007 at Yawzi Point. The results from 2003 were pooled between sites to describe the $D$. strigosa population in shallow water, but a two-site analysis was not possible in 2007 due to logistical constraints. Compari- 
son of the population structure between 2003 and 2007 must therefore be made with caution, as the temporal contrast is potentially biased by differences in spatial scale.

The populations of Porites astreoides and Diploria strigosa were described using size-frequency distributions, mean colony densities (colonies $\mathrm{m}^{-2}$ ), and the relative abundances of colonies in 3 size classes: I ( $\leq 40 \mathrm{~mm}$ diameter), II (41 to $80 \mathrm{~mm})$, and III ( $\geq 81 \mathrm{~mm})$. In these analyses (as with those focused on juveniles), size class I probably included congenerics, which could not be distinguished for the smallest colonies in this size category. The 3 size classes were selected to span the size range of colonies found on the reef, and to ensure that the individual classes were represented by similar numbers of colonies given the constraints of field time and areas of reef that could be censused. As a target sample size, the censusing and tagging were designed to provide $\geq 25$ colonies in each size class (Hughes 1984). However, demographic analyses with size-based matrices are prone to 2 sources of error arising from the choice of size classes: first, the 'error of estimation' caused by small size classes containing too few individuals and second, the 'error of distribution' caused by the distribution of individuals within the size class (Vandermeer 1978). Errors of estimation ( $\Psi$ ) arise from sampling errors when small numbers of individuals are used to estimate demographic rates, and errors of distribution $(\varphi)$ arise from probabilities of transitioning through size classes that are biased by individuals near to the lower or upper bounds of the size class. $\Psi$ declines with increasing size class, $\varphi$ increases with size class, and on a line plot of $\Psi$ and $\varphi$ against width of size class the errors are optimized where they cross (Vandermeer 1978). While $\Psi$ and $\varphi$ cannot be determined prospectively, retrospective analyses provide insight into the biases arising from the choice of size classes employed, and in the present study such analyses revealed that the 3 size classes provided a reasonable compromise between inherent errors and feasibility (Fig. S2 in the supplement).

To generate the data to populate size-based matrices with transition probabilities, starting in 1999, colonies of Porites astreoides were tagged and measured annually in surveys that were separate from, but in addition to, those completed more infrequently to quantify the overall population structure (described above). Tagged colonies were located the following year and evaluated for condition (alive versus dead), and if alive, measured and assessed for fission or fusion. If present, fission products were also measured. For tagging, colonies were selected haphazardly, marked with numbered aluminum tags epoxied to adjacent substratum, and the following year the tags were located using an underwater metal detector. New tags were applied annually to replace colonies that had died, or tags that were lost, thereby ensuring that the sample sizes remained close to 25 colonies in each size class. This procedure was applied to colonies of $P$. astreoides at Yawzi Point, Tektite, and Cabritte Horn between 1999 and 2007. The population of Diploria strigosa was analyzed in an identical way to $P$. astreoides, except that colonies were first tagged in 2002, at Yawzi Point and Tektite.

The results from the tagging procedure were used to construct $3 \times 3$ matrices corresponding to size classes I, II and III. For Porites astreoides, 8 separate matrices were created for the years between 1999 and 2007, and for Diploria strigosa, 5 separate matrices were created for the years between 2002 and 2007. Mortality rates were calculated for each size class, and in most cases, mortality ensured that the transition probabilities for each size class summed to $<1$; they can also sum to $>1$ for size classes II and III if colonies undergo fission (Hughes \& Tanner 2000). The matrices were used to calculate the intrinsic rate of population growth $(\lambda$, the dominant eigenvalue of each matrix) and the rate ( $\rho$, the ratio of the largest to the next largest eigenvalue) at which the population converged to a stable size structure (Hughes \& Tanner 2000, Caswell 2001). $\lambda$ and $\rho$ were calculated using PopTools 2.4 (www.cse.csiro. $\mathrm{au} / \mathrm{cdg} /$ poptools) running in Excel 2000. Without sexual recruitment, $\lambda$ measures the rate of population decline and has a value of $<1$, unless the rate of asexual proliferation exceeds mortality (Hughes \& Tanner 2000). As $\rho$ measures the rate of convergence to a stable size structure, its value is inversely related to the time necessary to achieve constant numbers of colonies in each size class. To determine which transition probability had the greatest effect on population growth $(\lambda)$, elasticity matrices were calculated using PopTools 2.4 from the equation:

$$
e_{i j}=a_{i j} / \lambda \times \partial \lambda / \partial a_{i j}
$$

where $e_{i j}$ is the elasticity of the $(i, j)$ entry of the sizebased matrix, and $a_{i j}$ is the $(i, j)$ transition probability in the matrix.

To determine confidence intervals for the demographic parameters, bootstrap resampling was employed. Each set of empirical data was resampled with replacement using a software routine added into Excel 2000 (www.resample.com), thereby creating 1000 additional sets of data. The 1000 sets of data were used to create the size-based matrices and to calculate mortality, $\lambda$ and $\rho$ as described above. The 1000 values of these parameters were used to calculate the $95 \% \mathrm{CI}$.

Population projections. Population projections were prepared in $1 \mathrm{yr}$ intervals by multiplying the population vector (standardized to $100 \mathrm{~m}^{2}$ of reef) by the matrix generated from the empirical data from 
2006-07, and completing the process iteratively. The 2006-07 matrix was used with the rationale that this was the most reliable descriptor of contemporary performance from which future population dynamics could be projected. With this procedure, the projected population vector at the end of each year was used as the starting vector for the next interval, and recruitment was added to the number of corals in size class I at the start of each iteration (Hughes 1984). Recruitment was assumed to be density independent (i.e. it was constant from year to year and unaffected by the density of coral colonies) because there was no empirical data with which this modification could be made. The population structure of each species was projected $100 \mathrm{yr}$ with the objective of exploring the effects of variable recruitment and differing disturbance regimes. The results of the projections were displayed as population densities by size class (colonies $100 \mathrm{~m}^{-2}$ ), and as proportional size-frequency distributions for the 3 size classes. To relate the population structure to percentage cover for each study species, the area of the colonies in each size class was estimated from the area of a circle with a diameter equal to half of the width of each size class $(20 \mathrm{~mm}$ for size class I, $60 \mathrm{~mm}$ for size class II) or, for size class III ( $\geq 81 \mathrm{~mm}$ diameter), an arbitrary value of $100 \mathrm{~mm}$ which was close to the median size of colonies in this size class in 2007. The area estimates for colonies in size class III resulted in a downward bias, which intensified as colonies grew to the upper extremes of size (ca. $180 \mathrm{~mm}$ diameter). The product of colony abundance and colony area, summed across size classes, was expressed as a percentage of the $100 \mathrm{~m}^{2}$ area covered by coral. In a few cases, projected coral cover converged on $100 \%$ when the entire benthos was covered by the species in question, and when this occurred before 100 yr has elapsed, further population growth was impossible.

Two sets of $100 \mathrm{yr}$ projections were completed for each species. The first involved simplified assumptions of steady state and/or variation in one determinant of population change, and the second involved more complex projections that simultaneously explored the impacts of 2 determinants of population change. In the first set of projections, 3 scenarios were explored. Scenario A evaluated the effects of 'no disturbance' conditions (i.e. those between 2006 and 2007) with recruitment estimated from the density of juvenile colonies recorded in 2007. Scenario B evaluated the effects of periodic disturbances, but was otherwise identical to Scenario A. Periodic disturbances were modeled from the effects of strong hurricanes that return to this region every 11 yr (based on St. Croix, US Virgin Islands, Treml et al. 1997), and Caribbean wide, typically cause a $17 \%$ reduction in coral cover (Gardner et al. 2005). The reduction in coral cover was created by proportionally reducing the number of colonies in each size class until cover declined $17 \%$; typically this involved the removal of 19 to $37 \%$ of the colonies. Recovery following these events was modulated by recruitment that was assumed unchanged by the disturbances. This is a reasonable assumption for a localscale disturbance that leaves $83 \%$ of the coral undamaged, and therefore capable of providing propagules in a biological system characterized both by selfrecruitment and larval import (Jones et al. 2009). Finally, Scenario C was identical to Scenario A, except that recruitment was estimated by reducing the density of juvenile corals to $10 \%$ of the 2007 level. These projections were designed to test the following hypotheses: (1) continuation of present conditions will result in an increased abundance (Scenario A), (2) periodic significant mortality will not greatly affect population growth (Scenario B), and (3) degraded recruitment will not result in declining population size (Scenario C).

In the second set of projections, recruitment was varied from low, to medium (the rates estimated from the density of juvenile corals in 2007) to high, and was crossed first with hurricanes having varying return times, and second with downward perturbations of the transition probability with the greatest effect on population growth $(\lambda)$. For Porites astreoides, recruitment was set at 59, 593 or 1000 colonies $100 \mathrm{~m}^{-2}$, and for Diploria strigosa, it was set at 1.6, 16, or 416 colonies $100 \mathrm{~m}^{-2}$. The return times of hurricanes was set at $5 \mathrm{yr}$, $11 \mathrm{yr}$ (the empirical return time for St. Croix, Treml et al. 1997), $20 \mathrm{yr}$, and infinity (i.e. there were no hurricanes), and in each case the storms reduced coral cover by $17 \%$ (as described above, Gardner et al. 2005). The transition probabilities with the greatest effect on $\lambda$ were identified from the elasticity values for the size-based matrices, and were reduced from the empirical value (from 2006-07) to 3 arbitrary values that supported a contrast of the effect on population growth. The impacts of the perturbations in the second set of projections were evaluated using coral cover (calculated as above) and the size-frequency distributions of colonies at the end of $100 \mathrm{yr}$. All projections commenced with the 2007 population vector and the 2006-07 size-based matrices unless otherwise stated. These projections were designed to explore (1) the sensitivity of the response to storms to varied recruitment, and (2) the sensitivity of population growth under differing recruitment regimes to varied success of the colonies with the greatest impact on population growth (which are the largest colonies, as described in 'Results').

Statistical analyses. Densities of juvenile corals and overall population densities for both species were compared among dates using one way ANOVA with 
square root $(x+3 / 8)$ (Zar 1999) transformations. Post hoc analyses were completed by Fisher's LSD method. The assumptions of the statistical procedures were tested using graphical analyses of residuals, and all analyses were completed using Systat 9.0 running in a Windows operating system. Changes in the sizefrequency distributions of colonies between the start and end of the projections were tested for significance using $\chi^{2}$ contingency tables.

\section{RESULTS}

\section{Density of juvenile corals as an estimate of recruitment}

Over the 14 yr study, the mean density of juvenile Porites spp. varied from $0.98 \pm 0.07$ to $1.64 \pm 0.11$ corals $0.25 \mathrm{~m}^{-2}\left( \pm \mathrm{SE}_{;} \mathrm{n}=200\right.$ and 241 , respectively), and differed among years $(F=1.933 ; \mathrm{df}=13,3022 ; \mathrm{p}=0.023)$ (Fig. 1). The density of juvenile Porites spp. was lower in 1994 compared to 1997-1999 and 2002-2005, and lower in 2006 compared to 2002 and 2003, but it was higher in 2002-2004 compared to 1995 and 2000 (post hoc analyses, $\mathrm{p}<0.05)$. Overall, there was an upward trend for the density of juvenile Porites spp., but the 14 yr period was marked by 2 striking declines; one over the 2 yr following 1998, and the other beginning in 2003 and ending in 2006 (Fig. 1). At the end of the study (2007), the mean density of juvenile Porites spp. had increased $51 \%$ compared to 1994.

Over the same period, the mean density of juvenile Diploria spp. ranged from $0.04 \pm 0.01$ to $0.16 \pm 0.02$

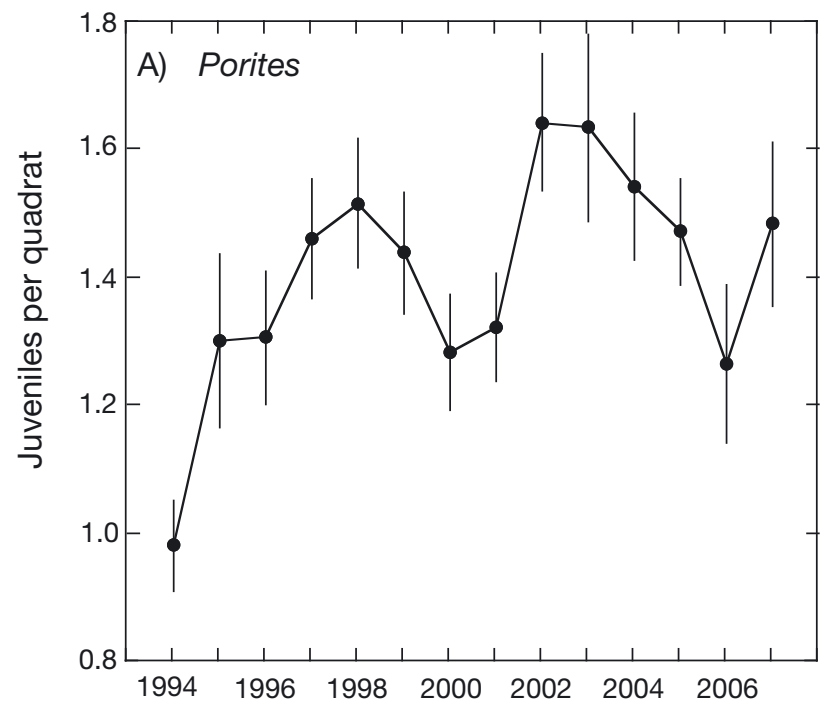

corals $0.25 \mathrm{~m}^{-2}( \pm \mathrm{SE} ; \mathrm{n}=240$ and 200 , respectively), and differed among years $(F=3.054 ; \mathrm{df}=13,3022 ; \mathrm{p}<$ 0.001). The density of juvenile Diploria spp. was lower in 2001-2007 compared to 1994, lower in 2004-2007 compared to 1996, lower in 2005-2007 compared to 1997, and lower in 2005-2007 compared to 1998-2000 (post hoc analyses, $\mathrm{p}<0.05$ ). In contrast to $P$. astreoides, there was a downward trend in the density of juvenile Diploria spp., including 3 periods of rapid loss (1994-95, 1997-98, and 2000-01). At the end of the study (2007), the mean density of juvenile Diploria spp. had decreased $76 \%$ compared to 1994 .

\section{Demographic analyses}

The first census of Porites astreoides in 1999 revealed a population with a mean density of $1.7 \pm$ 0.2 colonies $\mathrm{m}^{-2}( \pm \mathrm{SE}, \mathrm{n}=111$ quadrats $)$ and a positively skewed size-frequency distribution (Fig. 2). At this time, $60 \%$ of the corals were juveniles (size class I), and the biggest colony had a mean diameter of $31 \mathrm{~cm}$. For the 3 census years of 1999, 2003, and 2007, the population density changed $(F=23.875$; df $=2,225$; $<<$ 0.001), with mean densities increasing between 1999 and 2004, but then declining to 2007. These changes corresponded to a $254 \%$ increase in density from 1999 to 2003 , a $40 \%$ decline from 2003 to 2007 , and a $152 \%$ increase from 1999 to 2007. The changes in density occurred without changes in the size-frequency distributions, all of which remained positively skewed, although skewing was less pronounced in 2007 compared to 1999 and 2003 (Fig. 2).

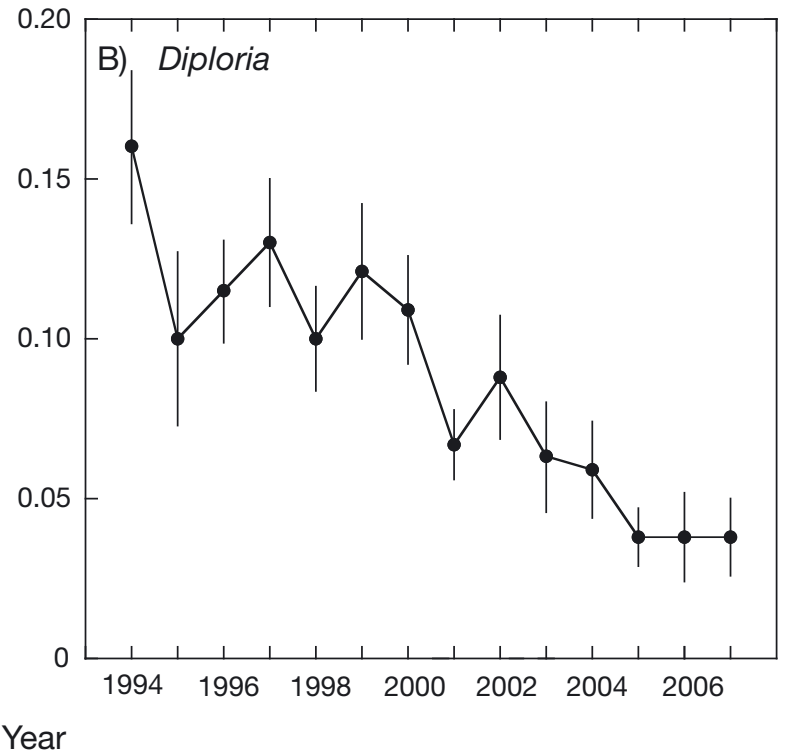

Fig. 1. Porites spp. and Diploria spp. Density of juvenile colonies on the reefs of St. John between 1994 and 2007 . Juvenile colonies were $\leq 40 \mathrm{~mm}$ diameter and were recorded annually in 200 to 240 quadrats, but with 80 in 1995 (quadrats = $0.5 \times 0.5 \mathrm{~m}$ ); mean $\pm \mathrm{SE}$ shown. Note that ordinates differ between graphs 


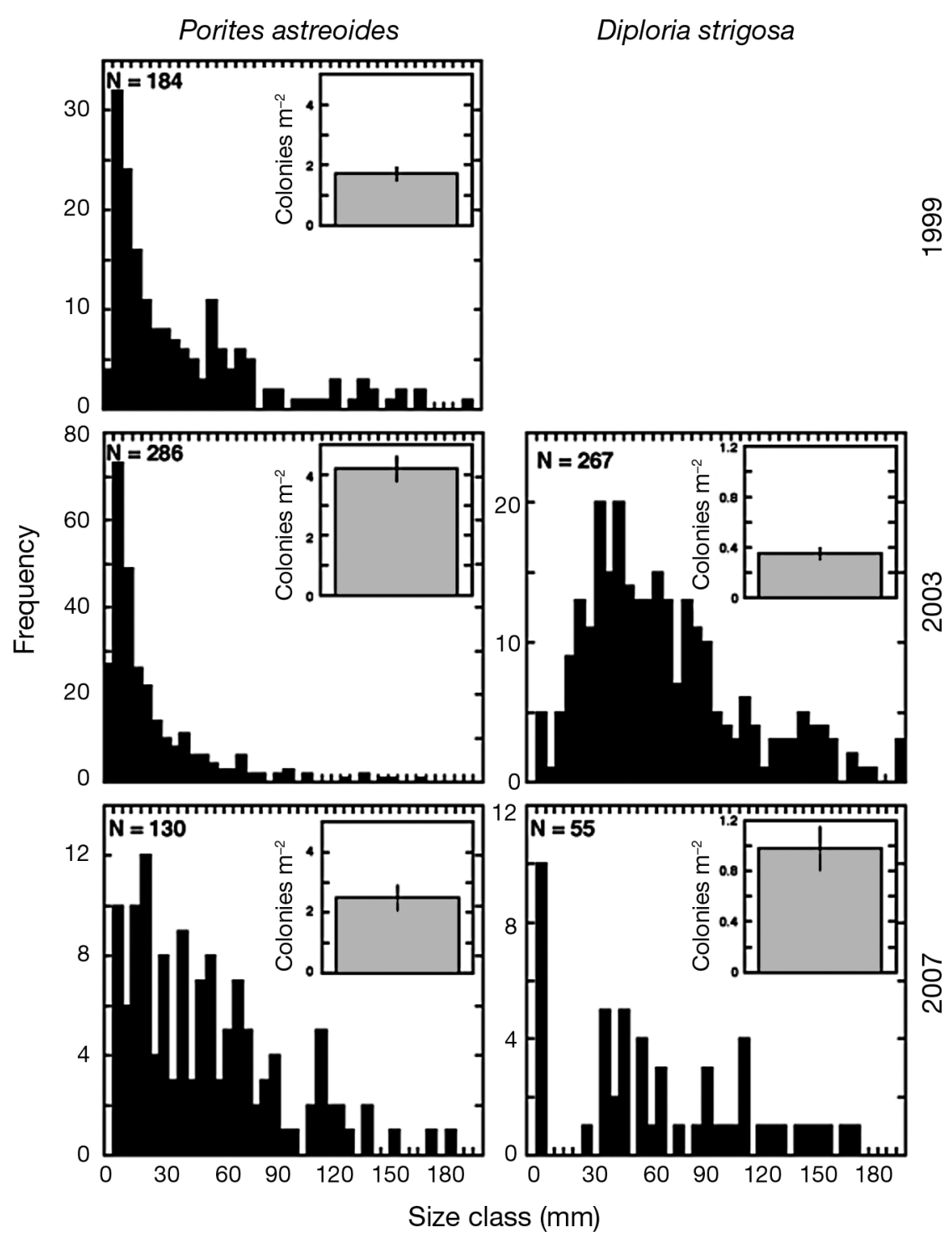

Fig. 2. Porites astreoides and Diploria strigosa. Size-frequency distributions and population densities on the reefs of St. John in 1999 ( $P$. astreoides only), 2003, and 2007. Distributions are shown for class intervals of $5 \mathrm{~mm}$ between 0 and $200 \mathrm{~mm}$, with the number of colonies $(\mathrm{N})$ shown in each panel. The upper size limit excluded a small number of large colonies $(\leq 4$ colonies distribution $^{-1}$ ), but improved clarity of presentation. The largest $P$. astreoides was $578 \mathrm{~mm}$ in diameter, the largest D. strigosa was $465 \mathrm{~mm}$ in diameter, and both were found in 2007. Population densities (insets: mean $\pm \mathrm{SE}$ ) show the number of colonies $\mathrm{m}^{-2}$ based on sample sizes (no. of quadrats) of 111 (1999), 69 (2003) and 48 (2007) for P. astreoides, and 78 (2003) and 46 (2007) for D. strigosa
Diploria strigosa was first censused in 2003, when the mean population density was $0.35 \pm 0.04$ colonies $\mathrm{m}^{-2}( \pm \mathrm{SE}, \mathrm{n}=78$ quadrats, $5 \times 2 \mathrm{~m})$, and the sizefrequency distribution was slightly positively skewed (Fig. 2). In contrast to Porites astreoides, only $18 \%$ of the population was in the juvenile stage in 2003, but the biggest $D$. strigosa (42 cm diameter) was comparable to the biggest $P$. astreoides encountered in the same year. The population of $D$. strigosa was censused again in 2007, but logistical constraints limited the analyses to Yawzi Point. Based on a smaller sampling effort in 2007 ( $\mathrm{n}=46$ quadrats, $1 \times 1 \mathrm{~m}$ ) compared to 2003, the population densities differed $(t=4.48$, df $=$ $122, \mathrm{p}<0.001)$. Although the differences in sampling efforts render comparison of the population densities in the 2 years problematic, the outcome nevertheless suggests the population increased in 2007, to $0.98 \pm$ 0.17 colonies $\mathrm{m}^{-2}$, and its size-frequency structure became more strongly positively skewed (Fig. 2).

For Porites astreoides, between 89 and 259 colonies were tagged annually, with 18 to 115 in size class I, 27 to 61 in size class II, and 41 to 83 in size class III (Table S1 in the supplement). The mortality rates were high for the smallest corals (14 to $24 \%$ ), but lower for size class II and III $(<12 \%)$, and in several years (2000-2002, 2003-2007) some of the differences among size classes were significant as determined from the non-overlapping confidence intervals (Fig. 3). Within each size class, there was no statistically discernable temporal trend in mortality, although the mortality of size class I colonies did decline to a minimum in 2002-03, and increase over the following $4 \mathrm{yr}$. None of the largest corals died in 3 of the $8 \mathrm{yr}$. 


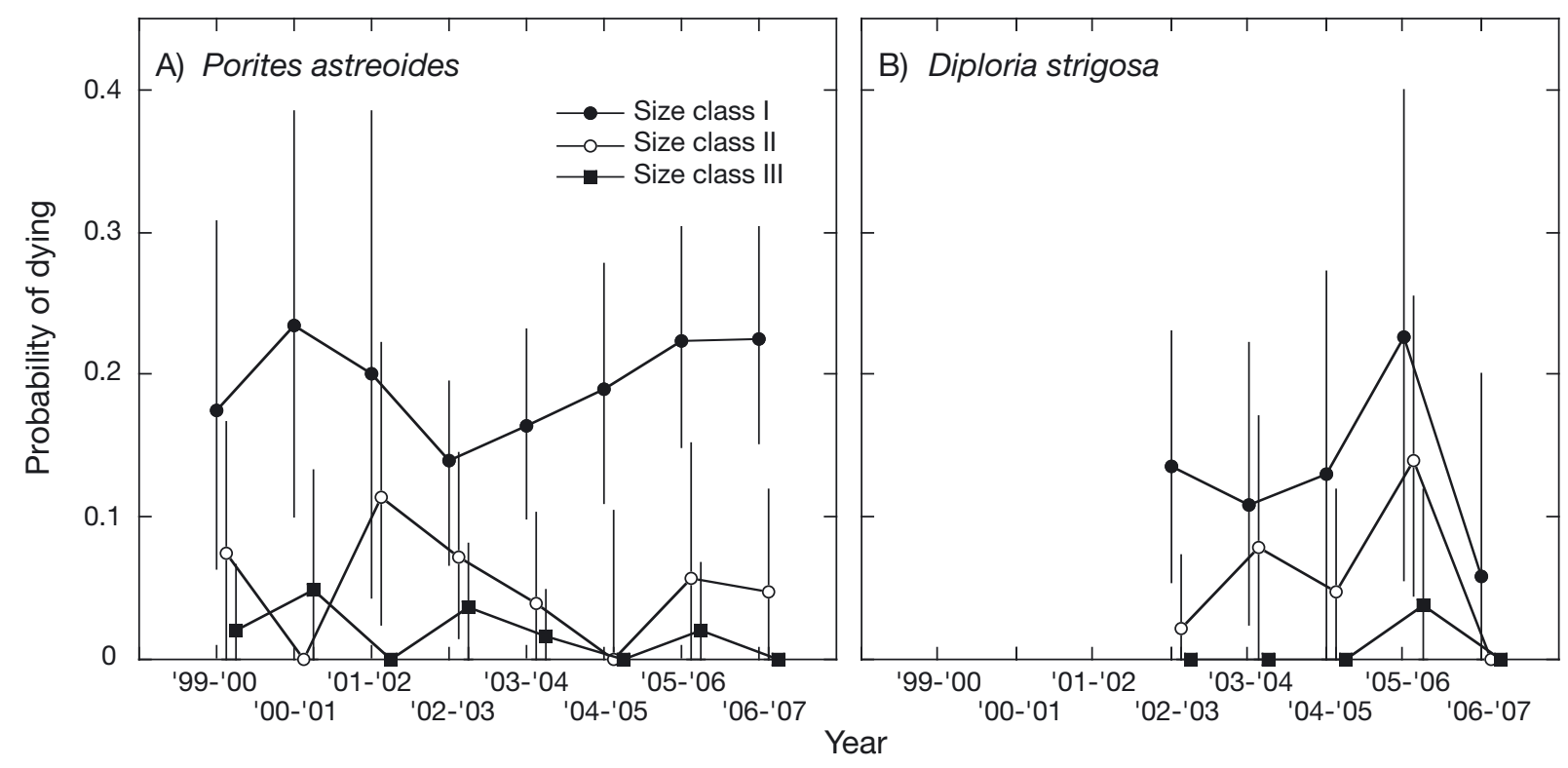

Fig. 3. Porites astreoides and Diploria strigosa. Mortality rates by size class for (A) P. astreoides and (B) D. strigosa on the reefs of St. John. Mean probabilities of dying are displayed together with the $95 \%$ CI, as determined from the 2.5 th and the 97.5 th percentiles of 1000 mortality rates generated by bootstrap resampling. Size classes are I ( $\leq 40 \mathrm{~mm})$, II (41 to $80 \mathrm{~mm})$, and III ( $\geq 81 \mathrm{~mm})$. The smallest size class for both taxa includes congenerics because species could not be resolved reliably for colonies at the lower end of this size range

For Diploria strigosa, between 91 and 122 colonies were tagged yearly, with 17 to 47 in size class I, 28 to 52 in size class II, and 17 to 26 in size class III (Table S2 in the supplement). Mortality was highest for the smallest corals (6 to $23 \%$ ) compared to size class II or III, and none of the largest corals died in 4 of the $5 \mathrm{yr}$ (Fig. 3). Based on the overlapping confidence intervals for mortality rates within a sampling period, the differences among size classes were not significant. Additionally, mortality of $D$. strigosa did not vary among years, although there was a trend for a reduction between 2005-06 and 2006-07 (Fig. 3).

The results of the tagging analyses for Porites astreoides were used to construct 8 size-based matrices for the years between 1999 and 2007, and for Diplora strigosa to construct 5 matrices for the years between 2002 and 2007 (Tables S1 \& S2). For both species, the transition probabilities varied only slightly among sampling periods (as shown by the small SEs; Fig. S3 in the supplement, see also Tables S1 \& S2), and in every case, the largest mean transition probabilities (i.e. $\geq 0.63$ ) described colonies remaining in the same size class; the mean probabilities of growing or shrinking to any other size class were smaller $(\leq 0.22)$ (Fig. S3). In most cases, and for both species, the probabilities of colonies in size classes II and III transitioning to smaller size classes were driven by colonies shrinking rather than undergoing fission. For $P$. astreoides, fission affected a few colonies in 1999-00 (1 colony), 2003-04
(3 colonies), 2004-05 (4 colonies), 2005-06 (5 colonies) and 2006-07 (4 colonies). For D. strigosa, fission was recorded for one colony in 2003-04, 2 colonies in each of 2002-03, 2004-05, and 2005-06, and 5 colonies in 2006-07. Fusion was rare among colonies of both species, with only one such event recorded in 2000-01 for $P$. astreoides.

The intrinsic rate of population growth $(\lambda)$ ranged from 0.95 to 1.02 for Porites astreoides, and from 0.93 to 1.06 for Diploria strigosa. Although the overlapping confidence intervals on these values suggest that there were no significant differences between pairs of sampling years (Fig. 4), $\lambda$ for $P$. astreoides displayed an upward trend and finished $\geq 1.0$ for the most recent year (2006-07), and for D. strigosa $\lambda$ increased to $>1.0$ after 2005-06. This upward trend was interrupted for $P$. astreoides in 2002-03 and 2003-04, and for D. strigosa in 2005-06. As $\lambda$ did not include the effects of recruitment (that were evaluated by addition of corals to the smallest size class), values $<1.0$ indicate a declining population, and values $\geq 1.0$ indicate a population increasing through fission. $\rho$ displayed contrasting trends over time for the 2 species, although in both cases these trends were not significant between pairs of sampling years, as assessed by the overlapping confidence intervals. For $P$. astreoides, $\rho$ declined from 1.64 in $1999-00$ to 1.25 in 2002-03, then increased to 1.55 in 2005-06, and finished the study in 2006-07 at 1.50 (9\% lower than recorded in 1999-00). In contrast, 

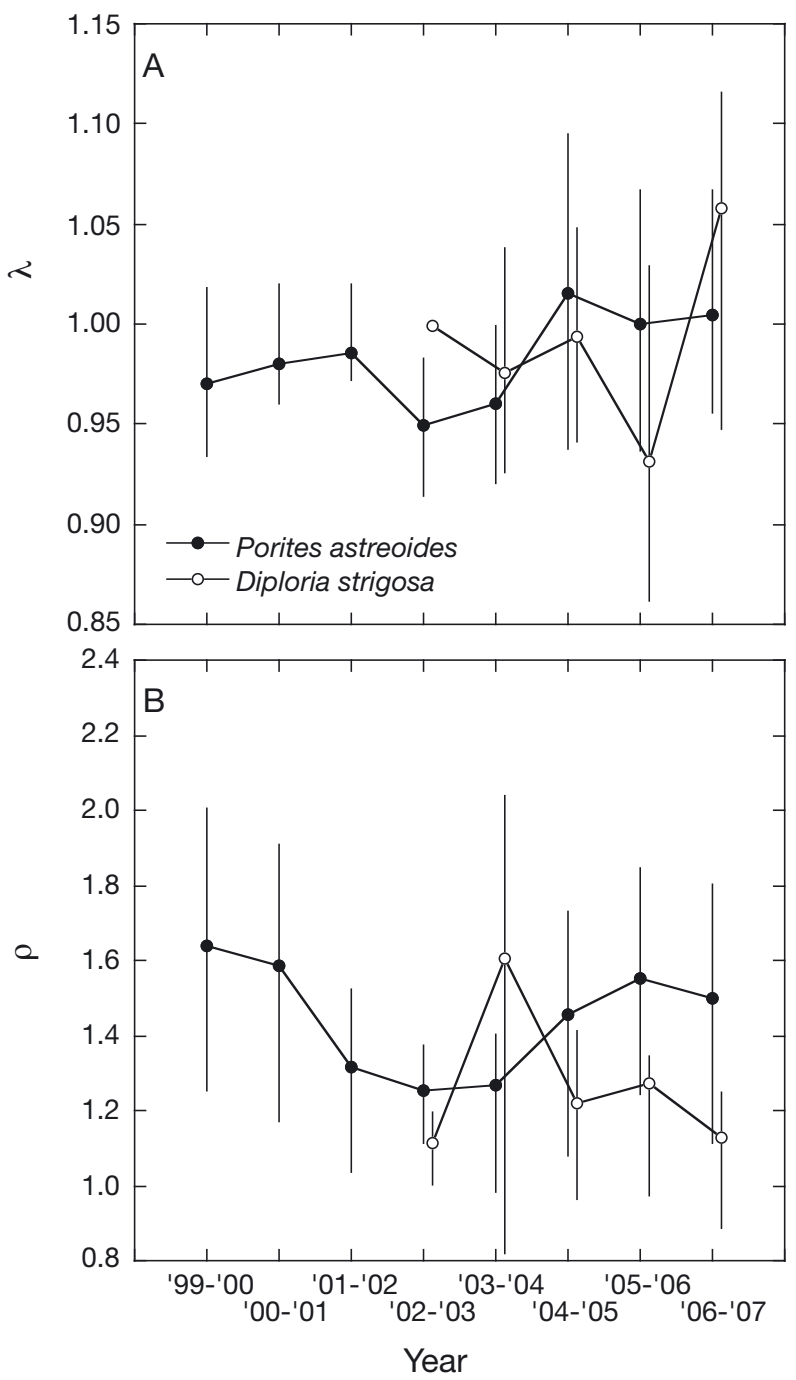

Fig. 4. Porites astreoides and Diploria strigosa. (A) Population growth rate $(\lambda)$ and $(\mathrm{B})$ damping ratios $(\rho)$ for $P$. astreoides and $D$. strigosa on the reefs of St. John. Values shown are the means together with the $95 \%$ CI. CIs were determined from the 2.5 th and the 97.5th percentiles of $1000 \lambda$ or $\rho$ values calculated from replicate matrices for each year that were prepared by bootstrap resampling the original data for either $8 \mathrm{yr}$ (P. astreoides) or 5 yr (D. strigosa)

for D. strigosa $\rho$ initially increased from 1.11 in 200203 to 1.60 in 2003-04, before declining to 1.13 in 2006-07 (2\% higher than in 2002-03).

The elasticities for both species and all 13 matrices revealed that $\lambda$ was strongly affected by colonies in size class III that remained in that size class (Table S3 in the supplement). For example, for Porites astreoides in 2006-07, the probability of size class III colonies remaining in this size class had an elasticity of 0.602 , the probability of size class II colonies remaining in this size class had an elasticity of 0.149 , and the remaining 7 transition probabilities had elasticities of $\leq 0.074$
(Table S3). For Diploria strigosa in 2006-07, the probability of size class III colonies remaining in this size class had an elasticity of 0.464 , the probability of size class II colonies remaining in this size class had an elasticity of 0.268 , and the remaining 7 transition probabilities had elasticities of $\leq 0.109$ (Table S3).

\section{Population projections}

Population projections for both species were characterized by increases in the number of colonies, elevated coral cover, and retention of the larger colonies (size classes II and III), regardless of the conditions investigated (Table S4 in the supplement, Figs. 5 \& 6). In the first set of projections, all scenarios for Porites astreoides began with 113 colonies in size class I, 81 in size class II, and 56 in size class III, and finished $100 \mathrm{yr}$ later with 12 to 108 -fold increases in the number of colonies; coral cover increased from $0.4 \%$ in 2007 to $7-61 \%$ in 2107 . In Scenario A, recruitment was estimated from the mean density of juvenile Porites spp. in 2007, which was $1.48 \pm 0.13$ per $0.25 \mathrm{~m}^{2}( \pm \mathrm{SE}, \mathrm{n}=240)$, and in this scenario, colony density increased 106-fold to cover $100 \%$ of the reef within $98 \mathrm{yr}$. The sizefrequency structure changed significantly $\left(\chi^{2}=27.6\right.$, $\mathrm{df}=2, \mathrm{p}<0.001$ ) because of increases in the number of colonies in size classes I and III. With consistent recruitment but periodic disturbances that reduced coral cover by $17 \%$ every 11 yr (Scenario B), population size repeatedly declined and recovered, and over 100 yr sustained a 42 -fold increase in colony density to cover $37 \%$ of the reef. The size-frequency structure changed significantly $\left(\chi^{2}=18.302, \mathrm{df}=2, \mathrm{p}<0.001\right)$, mostly because of an increase in the number of colonies in size class III. With a $90 \%$ reduction in recruitment but no disturbance (Scenario $\mathrm{C}$ ), the colony density increased 12 -fold in $100 \mathrm{yr}$ to cover $12 \%$ of the reef. The size-frequency structure changed significantly $\left(\chi^{2}=28.886, \mathrm{df}=2, \mathrm{p}<0.001\right)$ because of an increase in the number of colonies in size classes III.

The outcomes of scenarios A to C for Diploria strigosa in the first set of projections also revealed striking increases in population size, although for this species the changes were exponential (Fig. 5). The projections began with 17 colonies in size class I, 33 in size class II, and 50 in size class III, and after $100 \mathrm{yr}$ ended with $\sim 180$-fold increases in the number of colonies, and coral cover that increased from $0.2 \%$ in 2007 to $100 \%$ in 2107; none of the projections resulted in changes in the size-frequency structure of the population $\left(\chi^{2} \geq\right.$ 4.234, $\mathrm{df}=2, \mathrm{p} \geq 0.092$ ). In Scenario A, recruitment was estimated from the mean density of juvenile Diploria spp. in 2007, which was $0.04 \pm 0.01$ per $0.25 \mathrm{~m}^{2}( \pm \mathrm{SE}$, $\mathrm{n}=240$ ), and within $66 \mathrm{yr}$ colony density increased 


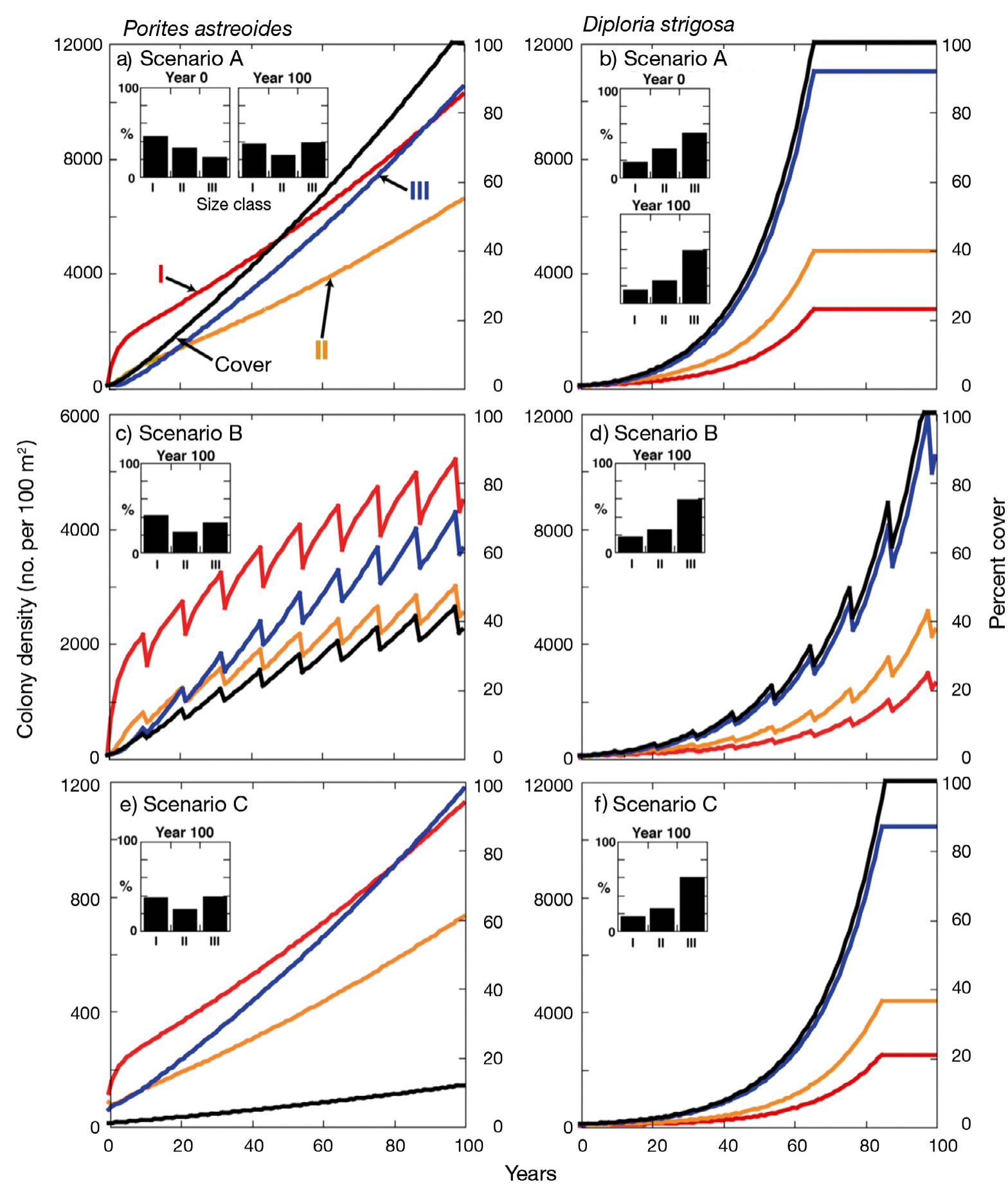

Fig. 5. Porites astreoides and Diploria strigosa. One hundred year population projections displaying colony density, coral cover, and size-frequency distributions of colony sizes (insets) under 3 sets of environmental conditions: (a,b) Scenario A, (c,d) Scenario B and (e,f) Scenario C. Projections were prepared from the 2006-07 matrices (Tables S1 \& S2 in the supplement) and an initial population vector for $100 \mathrm{~m}^{2}$ of reef in 2007; size classes are I ( $\leq 40 \mathrm{~mm}$ diameter, red), II (41 to $80 \mathrm{~mm}$, orange), and III ( $\geq 81 \mathrm{~mm}$, blue). Left ordinates are colony densities, and right ordinates are percentage cover (black line), and axes for $P$. astreoides differ between scenarios. Insets display percentage distribution of colonies among sizes classes (I, II and III) at the start of the projections (Year 0 in a \& b), and after 100 yr for each scenario. For P. astreoides, $100 \mathrm{~m}^{2}$ of reef in 2007 contained 113 colonies in size class I, 81 in size class II, and 56 in size class III; for D. strigosa, the same area contained 17 colonies in size class I, 33 in size class II, and 50 in size class III. Recruitment was applied annually to all projections, with the rates originating from empirical data in 2007. P. astreoides recruitment was set at 593 colonies $100 \mathrm{~m}^{-2}$ in Scenario A and B, and 59 colonies $100 \mathrm{~m}^{-2}$ in Scenario C; D. strigosa recruitment was set at 16 colonies $100 \mathrm{~m}^{-2}$ in Scenario A and B, and 1.6 colonies $100 \mathrm{~m}^{-2}$ in Scenario C 
184 -fold to cover $100 \%$ of the reef. With consistent recruitment but periodic disturbances that reduced coral cover by $17 \%$ every 11 yr (Scenario B), population size repeatedly declined and recovered, and over 100 yr sustained a 188-fold increase in colony density to cover $100 \%$ of the reef within 97 yr. Finally, with a $90 \%$ reduction in recruitment but no disturbance (Sce- nario $\mathrm{C}$ ), the population increased 182-fold to cover $100 \%$ of the reef within $86 \mathrm{yr}$.

In the second set of projections in which 2 conditions were simultaneously varied, populations of Porites astreoides and Diploria strigosa increased under all circumstances tested, although the magnitude of the effect was tempered by the combination of conditions

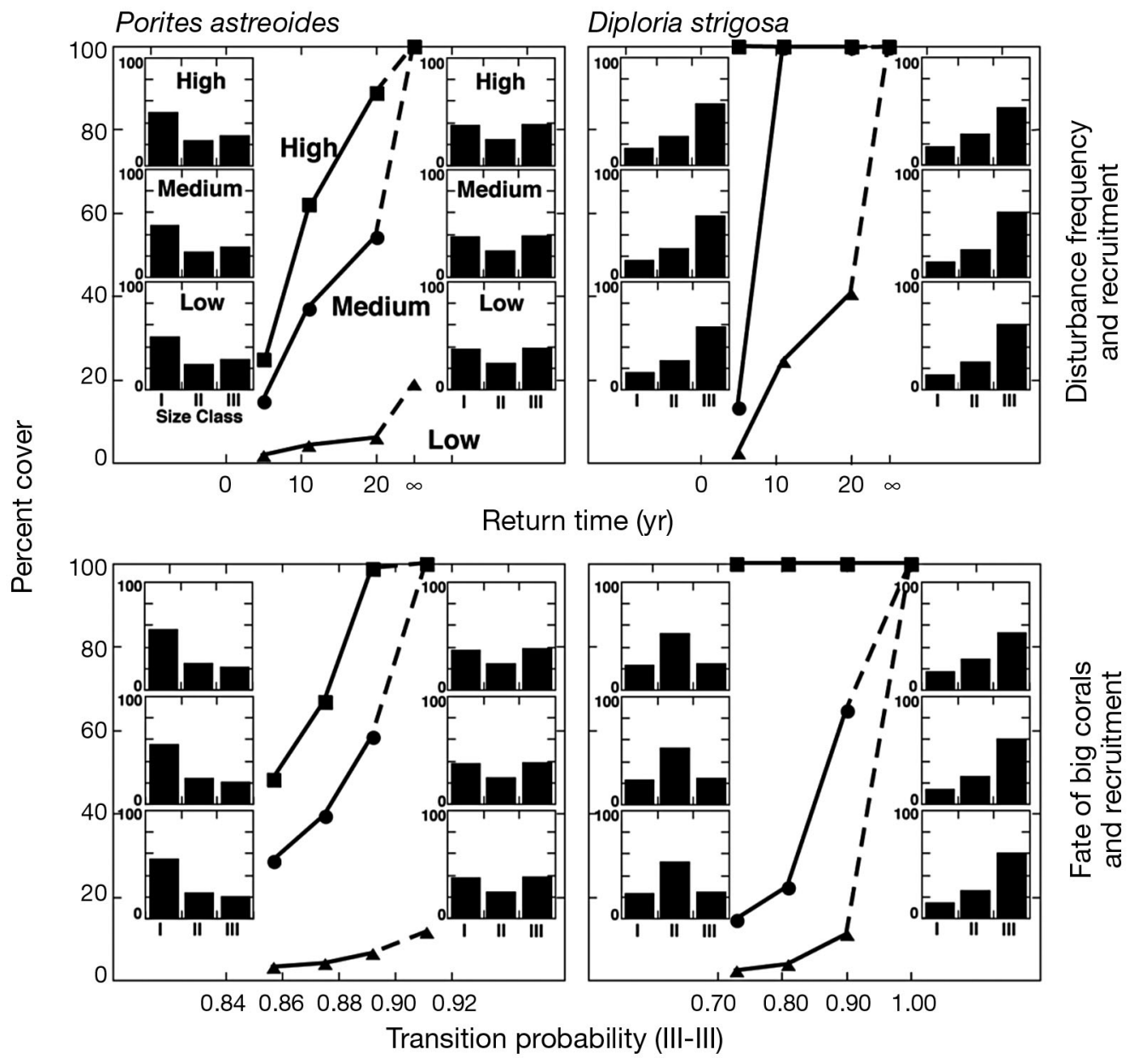

Fig. 6. Porites astreoides and Diploria strigosa. Population structure (percentage cover and size-frequency distributions of colony sizes) after $100 \mathrm{yr}$, based on projections from 2006-07 matrices (Tables S1 \& S2 in the supplement) and 2007 population vectors for $100 \mathrm{~m}^{2}$ of reef (as in Fig. 5). Percentage cover (main plots) shown for colonies summed across size classes in each projection, with size-frequency distributions (insets, left column using minimal values on the abscissa and right column using maximal values on the abscissa) showing percentage distribution of colonies among size classes (I, II and III); for clarity, lines and insets are labeled in top left panel only. Upper panels display the effects of hurricanes with varying return times crossed with variable recruitment. Hurricanes were modeled with return times of 5 yr, 11 yr (the mean for St. Croix over a 110 yr period ending in 1995, Treml et al. 1997), $20 \mathrm{yr}$ and infinity (i.e. there are no hurricanes), with each storm removing $17 \%$ of the coral cover (Gardner et al. 2005); dashed lines indicate the break between $20 \mathrm{yr}$ and infinity on the abscissa as categorical. Recruitment was modeled for $P$. astreoides at 59 colonies $100 \mathrm{~m}^{-2}$ (low, $\mathbf{\Delta}$ ), 593 colonies $100 \mathrm{~m}^{-2}$ (medium, ; the density of juvenile corals in 2007), and 1000

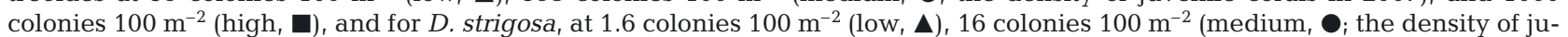
venile corals in 2007), and 416 colonies $100 \mathrm{~m}^{-2}$ (high, $\left.\mathbf{0}\right)$; the downwardly modified values represent a $90 \%$ reduction in recruitment, and the upper values an arbitrary higher value within the range recorded in quadrats in 2007 . Lower panels display the effects of changes in the transition probability (III-III) with the greatest effect on population growth (i.e. with high elasticities with regard to the effect on $\lambda$, the intrinsic rate of population growth; Table S3 in the supplement) crossed with variable recruitment. Variation in the III-III transition probability was modeled using 3 downward perturbations from the 2006-07 value, which for P. astreoides were 0.911 (for 2006-07), 0.892, 0.875, and 0.857, and for D. strigosa, 1.000 (for 2006-07), 0.900, 0.810, and 0.729. Recruitment was modified as in the projections under differing hurricane regimes (upper panels) 
employed (Fig. 6). Under some conditions, both species occupied $100 \%$ of the reef in 100 yr. More frequent disturbances (e.g. hurricanes every 5 yr that removed $17 \%$ of the coral cover) reduced the percentage cover of $P$. astreoides and D. strigosa after $100 \mathrm{yr}$, with $\leq 2 \%$ cover being produced with low recruitment and disturbances every 5 yr. Enhanced recruitment alleviated the impacts of disturbances, with the effects intensifying as disturbances become less common, particularly for $D$. strigosa for which the largest colonies had high probabilities of survival $(>0.813$, Table S2). Varying regimes of disturbance and recruitment significantly altered the size-frequency structure of $P$. astreoides after $100 \mathrm{yr}\left(\chi^{2} \geq 7.423, \mathrm{df}=2, \mathrm{p} \leq 0.024\right)$, leading to enhanced representation of the smallest (size class I) and largest (size class III) colonies; the size-frequency structure of $D$. strigosa was unaffected $\left(\chi^{2} \leq 4.762, \mathrm{df}=\right.$ $2, \mathrm{p} \geq 0.092$ ).

The transition probabilities describing the fate of the largest colonies (size class III) had the strongest effect on $\lambda$ (Table S3) and, therefore, these values were modified to evaluate the interactive effects with recruitment on population growth. For Porites astreoides, $100 \mathrm{yr}$ projections were completed with this transition probability reduced from the empirical value in 2006-07 (0.911) to $0.892,0.875$, and 0.857 (a maximum reduction of $6 \%$ ), and for D. strigosa, from 1.000 (the value in 2006-07) to $0.900,0.810$ and 0.729 (a maximum reduction of $27 \%$ ). By applying these values to the sizebased matrices, the outcomes simulated enhanced mortality of the large colonies (rather than fission). Under low and medium recruitment, reductions in the III-III transition had strong effects on coral cover after $100 \mathrm{yr}$, for example, with the largest reductions at medium recruitment causing cover to decline from $100 \%$ (with the III-III transition $=0.911$ ) to $29 \%$ for P. astreoides, and for D. strigosa from $100 \%$ (with the III-III transition $=1.000$ ) to $14 \%$. At high recruitment, the absolute (but not relative) effect of reducing the III-III transition to the greatest extent was lessened for P. astreoides, causing cover to decline from $100 \%$ to $29 \%$. For D. strigosa, high recruitment maintained coral cover at $100 \%$, and conferred resistance to changes in the III-III transition. For both species, the size-frequency structure of the populations after $100 \mathrm{yr}$ were altered significantly $\left(\chi^{2} \geq 6.396, \mathrm{df}=2, \mathrm{p} \leq 0.041\right)$ when the lowest values of the III-III transition were applied, regardless of recruitment; small colonies became more abundant for $P$. astreoides, and the medium-sized colonies became more abundant for $D$. strigosa. The projections using the empirical value of the III-III transitions were identical to those modeled for no disturbance (upper panels, Fig. 6), and as described above, caused changes in the size-frequency structure for $P$. astreoides but not $D$. strigosa.

\section{DISCUSSION}

This study reveals population growth for 2 Caribbean corals over the last 4 to $7 \mathrm{yr}$, and projects substantial further growth over the next century. These outcomes are biologically significant, because they contrast with the declining coral cover that has characterized many tropical reefs over the last few decades (Gardner et al. 2003, Bruno \& Selig 2007, HoeghGuldberg et al. 2007), and provide a demographic context within which contemporary (and ongoing) changes in coral species assemblages (Loya et al. 2001) can be better understood. While the corals studied, Porites astreoides and Diploria strigosa, exhibited broadly similar past and projected population trajectories, these outcomes were achieved through different mechanisms. Porites astreoides possesses features that are characteristic of weedy species (Grime 1977, Knowlton 2001), which favors population growth under adverse conditions. In contrast, D. strigosa does not conform well to this functional group because it has a broadcast spawning reproductive strategy (Szmant 1986) and recruits at relatively low densities (Smith 1992), although it grows at a rate similar to $P$. astreoides (i.e. 2 to $14 \mathrm{~mm} \mathrm{y}^{-1}$ at $\leq 5 \mathrm{~m}$ depth, Huston 1985).

In evaluating which corals might survive the current suite of environmental assaults affecting tropical marine environments, it is noteworthy that both Porites astreoides and Diploria strigosa may be included in this group, even though they differ in phylogeny (Poritidae versus Faviidae, see Fukami et al. 2008) and life history strategies (e.g. brooding versus broadcasting). The dissimilarities between $P$. astreoides and D. strigosa suggest that ecological winners (sensu Loya et al. 2001) among scleractinians on contemporary reefs might be determined by traits more subtle than those associated simply with a weedy life history strategy (Knowlton 2001). For example, success under adverse conditions might be enhanced by thick tissue as is found in poritids (Edmunds 2008, Mydlarz et al. 2010), or for D. strigosa, the possession of unknown mechanisms conferring resistance to certain combinations of chronic adverse conditions (Bythell et al. 1993). Another factor potentially affecting the success of corals is the genetic identity of their Symbiodinium symbionts (Jones et al. 2008), but in the case of $P$. astreoides and D. strigosa, a consistent pattern in this characteristic is absent. P. astreoides in St. John contains Symbiodinium genotypes A4 and A4a (Green et al. 2010), which are uncommon among Caribbean corals (LaJeunesse 2002), whereas D. strigosa typically contains the ubiquitous genotypes B1 and C1 (La-Jeunesse 2002).

Against this backdrop, it seems unlikely that any one coral species will enjoy success in the complex spatio- 
temporal mosaic of environmental challenges now affecting coral reefs, and indeed, in contrast to the population growth of Diploria strigosa in St. John, elsewhere in the Caribbean this species has recently been susceptible to thermal bleaching (Wilkinson \& Souter 2008, Brandt 2009). Nevertheless, if aspects of the results from St. John can be generalized to other Caribbean locations, and Porites astreoides and D. strigosa are matched with taxa having comparable demographic properties in the Pacific, the present analysis lends support to the notion that a small suite of physiologically robust corals might allow coral reefs to persist longer than has been predicted (Pandolfi et al. 2005, Hoegh-Guldberg et al. 2007). Implicit in this possibility is that reefs of the future will have coral species assemblages differing from those that have prevailed in the recent past. In such modified configurations, the strong likelihood that changes will occur in the ecological processes (e.g. rates of accretion, susceptibility to wave damage) structuring coral reefs, at least compared to those that have prevailed in the recent past, warrants urgent research attention.

Porites astreoides belongs to a functional group of Porites spp. that produce massive colonies on reefs throughout the world (Veron 2000), but they are best known from the Pacific where they are dominant components of several reef habitats (Done \& Potts 1992). In the Pacific, massive Porites spp. build colonies up to $12 \mathrm{~m}$ tall (Soong et al. 1999) and $17 \mathrm{~m}$ wide (Brown et al. 2009), with considerable ecological importance (Done 1988, Done \& Potts 1992). Based on the great age of the largest Pacific Porites spp., it is reasonable to infer that they are resistant to routine environmental assaults that occur during their life span (Lough \& Barnes 1997), at least compared to many other scleractinians. In the Caribbean however, even the largest P. astreoides (at least $1000 \mathrm{~cm}^{2}$, Hughes \& Jackson 1985) is an order of magnitude smaller than large Porites spp. in the Pacific, but like their Pacific congeners, $P$. astreoides can be quite resistant to environmental assaults (Tomascik \& Sander 1987, Wittenberg \& Hunte 1992). Such resistance has probably been a factor contributing to the increase in relative abundance of this species throughout the Caribbean over the last $30 \mathrm{yr}$ (Green et al. 2008), and possibly since the Pleistocene (Pandolfi \& Jackson 2006). Consistent with this region-wide trend, the present study demonstrates that the density of juvenile Porites spp. (of which $>66 \%$ are likely to be $P$. astreoides, described in 'Results') increased 1.7-fold between 1994 and 2007. Although declines in the abundance of juvenile Porites spp. followed in 1998 and 2005, both of which were unusually warm years and characterized by severe coral bleaching throughout the Caribbean (Donner et al. 2007, Brandt 2009), these declines were transient.
Nevertheless, the 2005 Caribbean-wide bleaching event led to high mortality of some corals in St. John (Miller et al. 2009) - notably Montastraea annularis complex, Colpophyllia natans and Agaricia agaricites - and severely affected Diploria strigosa and $P$. astreoides on inshore patch reefs of the Florida Keys (Brandt 2009) and reefs (3 to $30 \mathrm{~m}$ depth) at Buck Island National Monument, St. Croix (Clark et al. 2009). It is therefore surprising that the demographic consequences of this event for $D$. strigosa and $P$. astreoides in St. John were relatively minor (present study, Figs. 1 to 4), and this outcome highlights the importance of understanding the influence of local conditions and recent history in determining the population trajectories for reef corals. Unfortunately, the fieldwork for the present project ended before the severe bleaching of 2005 was recorded between September and November (Miller et al. 2009) and, therefore, it is unknown to what extent the populations of $D$. strigosa and $P$. astreoides bleached between the surveys of 2005 and 2006.

As juvenile corals were defined as colonies $\leq 40 \mathrm{~mm}$ diameter, and might be up to $11 \mathrm{yr}$ old (Edmunds 2007), they are an imperfect proxy for recruits. Unfortunately, measuring the actual density of coral recruits on natural surfaces, as well their survivorship, is exceedingly difficult and arguably impossible at a taxonomic resolution of species. However, one mechanism to evaluate the discrepancy in recruitment estimated from juvenile corals versus actual recruits is to sample the water column for competent larvae using settlement tiles. In St. John, settlement tiles $(15 \times 15 \mathrm{~cm})$ deployed for 6 month intervals on the shallow reefs along the south coast between 2006 and 2008 revealed Porites spp. recruits at densities equivalent to $12-$ 60 corals $\mathrm{m}^{-2}$ (Green 2009). These densities are about 1.9 to 9.4 -fold higher than the greatest density of juvenile Porites spp. on adjacent reef surfaces between 1994 and 2007. Diploria spp. recruits were not detected on these tiles, but the low densities of juvenile Diploria spp. during this period $\left(0.16\right.$ corals $\left.\mathrm{m}^{-2}\right)$ suggests that recruits of this taxon might have avoided detection on small settlement tiles, even if they occurred at $\sim 10$-fold higher densities than juveniles. While it is certain that more Porites spp. and Diploria spp. recruited to the reefs of St. John than was indicated by the density of juveniles, it is also likely that large numbers succumbed to post-settlement mortality (Hunt \& Scheibling 1997, Dunstan \& Johnson 1998, Vermeij \& Sandin 2008) before being detected. Therefore, there is no easy way to relate densities of corals in these 2 life stages. In part, it was uncertainty over the rates of recruitment of Porites spp. and Diploria spp. that motivated the population projections under differing recruitment regimes (Figs. $5 \& 6$ ), and it is striking that 
these projections revealed population growth under virtually all conditions tested.

For Porites astreoides, the most likely fate of corals over a single year was to remain in the same size class (mean transition probability $\geq 0.661$ ), with the probabilities of growing or shrinking being considerably smaller $(\leq 0.194)$. Shrinkage is biologically significant as it represents a demographic sink removing bigger colonies that have a low chance of dying, and places them into smaller size classes that have a higher chance of dying. Although the causes of shrinkage are unknown, most colonies appeared to shrink by tissue retraction at the colony margins, and relatively few colonies underwent fission $\left(<2.6 \% \mathrm{yr}^{-1}\right)$ (cf. Bythell et al. 1993). Overall, the results from tagged $P$. astreoides generated 8 size-based population matrices between 1999 and 2007, for which $\lambda$ varied from 0.949 (in 2002-03) to 1.005 (in 2006-07). Although the P. astreoides population was unable to grow without recruitment prior to 2004 (i.e. $\lambda<1$ ), after 2004 the population was able to grow (i.e. $\lambda>1$ ) independent of sexual recruits. This counterintuitive outcome was driven by (1) fission, which produced smaller colonies, some of which were functionally indistinguishable from recruits (as defined here) and contributed to size class I, and (2) low rates of mortality of big colonies, which were influential in population growth as shown by the high elasticities associated with stasis of these colonies (Table S3). Together, these effects acted consistently throughout the study, thereby sustaining a relatively consistent tempo of population change ( $\rho$ ).

In contrast to Porites astreoides, the density of juvenile Diploria spp. declined rapidly at 0.01 colonies $\mathrm{yr}^{-1}$, and sustained a $76 \%$ reduction between 1994 and 2007. It is unknown why this decline occurred, although it must inevitably be a product of an imbalance between mortality and recruitment. The annualized mortality of juvenile $D$. strigosa ( 0 to $29 \% \mathrm{yr}^{-1}$ ) is low compared to other Caribbean corals (Bak \& Engel 1979, Edmunds 2004), but it is sufficient to account for a large portion of the decline in abundance of this life stage (e.g. the density of juvenile Diploria spp. declined $38 \%$ between 1994 and 1995), and its effects in reducing the density of juvenile colonies may have been augmented by declining larval recruitment or high post-settlement mortality. Evaluating these competing possibilities may be challenging, as previous studies suggest that D. strigosa routinely recruits at low densities, even when adult colonies are a significant component of the coral community (e.g. in Bermuda) (Smith 1992).

A leading cause of the population growth for Diploria strigosa is the juxtaposition of low recruitment and low mortality of colonies in all size classes ( $\leq 23 \%$ over the $5 \mathrm{yr}$ ), and the large number in the biggest size class that remain in this size class over each year $(\geq 81 \%$ for the 5 yr over which colonies were monitored). While the results from 2 of the years (2002-03 and 2006-07) show that all of the biggest corals remain in the biggest size class (i.e. transition probabilities $=1.0$ ) and do not die (mortality $=0 \%$ ), this is probably an artifact of the relatively small number of large colonies that were censused repeatedly over year-long periods, and should not be interpreted to suggest that these colonies are immortal (which obviously is incorrect, Bythell et al. 1993). While censusing more big $D$. strigosa colonies (i.e. in size class III) over multiple years would likely detect measurable whole-colony mortality, the consistent results from $5 \mathrm{yr}$ of censusing in the present study (Table S2) suggest that more accurate estimates of mortality rates might not depart greatly from zero.

The scenarios explored in the first set of population projections tested 3 hypotheses describing ecologically relevant possibilities for St. John. First, under Scenario A that extended 2007 conditions, populations of Porites astreoides and Diploria strigosa both grew to cover $100 \%$ of the reef. In Scenario B, with periodic and recurrent disturbances, which were modeled to leave $\sim 83 \%$ of the coral cover undamaged and leave open the opportunity for self-seeding and recruitment of larvae from more distant locations, populations of $P$. astreoides and D. strigosa recovered quickly from each disturbance to occupy $37 \%$ and $100 \%$ of the reef, respectively. Finally in Scenario C, with a $90 \%$ reduction in recruitment as might occur with a regionalscale disturbance, the populations of both species continued to grow until $12 \%$ and $100 \%$, respectively of the reef was covered within $100 \mathrm{yr}$.

While the second set of more complex projections confirmed the outcomes of the more simple projections, namely that Porites astreoides and Diploria strigosa are poised to increase in abundance in St. John, they also provide insight into the complexity of interactive effects that can modulate the magnitude of this outcome. For instance, with low recruitment, variation in the return time of storms has small effects on coral cover after $100 \mathrm{yr}$, although in the absence of storms, D. strigosa can occupy $72 \%$ of the reef even when recruitment is low. As rates of recruitment intensify, variation in the return time of storms has a stronger effect in modifying coral cover, although the highest recruitment confers relative immunity to frequent storms for $D$. strigosa. Recruitment can also alter coral cover depending on the fate of the largest colonies (described by the III-III transition probability), with small changes in the III-III transition affecting the projections for $P$. astreoides at medium and high recruitment, and the projections for $D$. strigosa at medium and low recruitment. These projections reveal the vulnerability of rapid population growth of these species to small changes in the success of the largest colonies. 
While the recent past provides little reason to suspect the III-III transitions are prone to large changes (Fig. S3), the appearance of a novel pathogen might cause the changes in this value necessary to reduce population growth, even at low infection rates.

In addition to revealing the diverse sets of conditions under which populations of Porites astreoides and Diploria strigosa can grow over the next $100 \mathrm{yr}$, the projections also highlight 2 additional outcomes of interest. First, they demonstrate that large colonies are retained in the populations under all projection conditions explored, with substantial increases in the abundance of small colonies only being recorded for $P$. astreoides when the proportion of big colonies remaining in the largest size declined from 0.91 to 0.86 (Fig. 6). Large colonies contribute greatly to reef structure, and bigger colonies have greater fecundity (Hall \& Hughes 1996) and, therefore, their occurrence has substantial ecological importance. The effects of environmental conditions on the size-frequency structure of coral populations have received considerable attention (Bak \& Meesters 1999, Done 1999), and it is clear that differing combinations of environmental conditions and coral species can result in contrasting outcomes. Faced with disturbance regimes, the populations of some corals become negatively skewed (Bak \& Meesters 1999) while others become positively skewed (Edmunds \& Elahi 2007). The present study reveals the demographic mechanisms (i.e. the great longevity of large colonies and their resistance to fission set against a backdrop of at least low recruitment) affecting the size structure of coral populations on a centennial scale, and for the species studied, suggests that weakto-strong negative skewing may not necessarily be disadvantageous (cf. Bak \& Meesters 1999, Meesters et al. 2001). Second, by extending the projection period to $100 \mathrm{yr}$, the present study identifies some conditions under which $P$. astreoides and $D$. strigosa theoretically could each cover $100 \%$ of the reef. Clearly this is an impossible outcome, if only because these are sympatric taxa, and it underscores the importance of including biological complexity - such as density dependence and competition (Tanner et al. 2009) - into population projections for reef corals.

The projections described here support the conclusion that population growth for Porites astreoides and Diploria strigosa may be robust to changes in the assumptions regarding disturbance regimes and recruitment. This outcome differs markedly from the poor prognosis for reef health that stems from the current condition of reefs in the Caribbean (Gardner et al. 2003) and Pacific (Bellwood et al. 2004, Bruno \& Selig 2007), as well as the population projections for the Caribbean coral Montastraea annularis (Hughes \& Tanner 2000, Edmunds \& Elahi 2007). In Jamaica,
Hughes \& Tanner (2000) studied a deep-water (35 m) population of $M$. annularis from 1977 to 1993; over this period the percentage cover of this species declined from $\sim 20 \%$ to $\sim 6 \%$, and $57 \%$ of the colonies died. Hughes \& Tanner (2000) constructed size-based matrix models over 5 yr intervals and demonstrated that the rate of population increase $(\lambda)$ declined from 1.074 (1977-82) to 0.388 (1987-93); they used the final interval of their study to project population collapse within $\approx 20$ yr. The outcomes of the demographic analysis of Edmunds \& Elahi (2007) for a M. annularis population in shallower water (9 m) in St. John between 1987 and 2003 are similar to those of Hughes \& Tanner (2000), namely in showing a decline in cover from $43 \%$ (1988) to $12 \%$ (2003), a reduction in $\lambda$ from 0.661 (1988-93) to 0.581 (1998-03), and a projected population collapse within $50 \mathrm{yr}$. Ecologically, $M$. annularis is unlike $P$. astreoides and $D$. strigosa, because it is an important reef building coral throughout the region (Goreau 1959), its colonies can be substantially larger and, demographically, it is characterized by long-lived colonies, frequent fission, and poor recruitment (Hughes \& Tanner 2000, Edmunds \& Elahi 2007). The size and age of colonies in St. John provides an effective illustration of the contrast between $M$. annularis and $P$. astreoides/D. strigosa, for while there are many colonies of $M$. annularis in Great Lameshur Bay that are ca. $1 \mathrm{~m}$ tall and probably $>100 \mathrm{yr}$ old (Edmunds \& Elahi 2007), most colonies of $P$. astreoides and D. strigosa are $<8 \mathrm{~cm}$ diameter (this study, see also Hughes \& Jackson 1985, Bythell et al. 1993) and with growth rates of 2 to $14 \mathrm{~mm} \mathrm{yr}^{-1}$ (Huston 1985) are probably only 6 to $40 \mathrm{yr}$ old. Elucidating the mechanistic bases of these striking differences in population trajectories will need to be a research priority in order to understand why historically dominant corals like $M$. annularis are being replaced by corals that are either weedy (e.g. P. astreoides) or more physiologically robust (e.g. D. strigosa).

To understand how tropical coral reefs will change over the next century (and beyond), demographic models of coral species will be required in order to project coral population structure into the future with a high degree of confidence. Additionally, demographic models can serve roles in comparative approaches designed to identify species with the capacity to succeed under adverse conditions, and to identify the demographic traits favoring resistance to environmental assaults. Demographic models should play central roles in the monitoring of coral reefs, the implementation of marine protected areas encompassing significant coral populations, and in the United States, the debate regarding listing coral species as threatened or endangered under the Endangered Species Act (Federal Register 2010). 
Acknowledgements. The research was completed with support from multiple sources, most significantly from the Long Term Research in Environmental Biology program of the US National Science Program (DEB 03-43570 \& DEB 08-51441), the University of Puerto Rico Sea Grant Program (R-101-2-02 \& R-101-1-06). Writing and analysis was assisted by NSF OCE 04-17412. The work was made possible by several generations of graduate students, support from R. Boulon, C. Rogers, V. Powell, S. Prosterman, and R. Lockhart, and benefited greatly from the comments of 4 anonymous reviewers. I am grateful to R. Brown and the staff of the Virgin Islands Ecological Resource Station (VIERS) for making our visits to St. John productive and enjoyable. This is contribution number 166 of the marine biology program of California State University, Northridge.

\section{LITERATURE CITED}

Andres NG, Rodenhouse NL (1993) Resilience of corals to hurricanes: a simulation model. Coral Reefs 12:167-175

Aronson RB, Precht WF (2001) White-band disease and the changing face of Caribbean coral reefs. Hydrobiologia 460:25-38

Baird AH, Salih A, Trevor-Jones A (2006) Flourescence census techniques for the early detection of coral recruits. Coral Reefs 25:73-76

Bak RPM, Engel MS (1979) Distribution, abundance and survival of juvenile hermatypic corals (Scleractinia) and the importance of life history strategies in the parent community. Mar Biol 54:341-352

Bak RPM, Meesters EH (1999) Population structure as a response of coral communities to global change. Am Zool 39:56-65

Bellwood DR, Hughes TP, Folke C, Nyström M (2004) Confronting the coral reef crisis. Nature 429:827-833

Brandt ME (2009) The effect of species and colony size on the bleaching response of reef-building corals in the Florida Keys during the 2005 mass bleaching event. Coral Reefs 28:911-924

Brown BE (1997) Adaptation of reef corals to physical environmental stress. Adv Mar Biol 31:221-299

Brown DP, Basch L, Barshis D, Forsman Z, Fenner D, Goldberg J (2009) American Samoa's island of giants: massive Porites colonies at Ta'u island. Coral Reefs 28:735

Bruno JF, Selig ER (2007) Regional decline of coral cover in the Indo-Pacific: timing, extent, and subregional comparisons. PLoS ONE 2:e711

Buddemeier RW, Fautin DG (1993) Coral bleaching as an adaptive mechanism: a testable hypothesis. BioScience 43:320-326

Bythell JC, Gladfelter EH, Bythell M (1993) Chronic and catastrophic natural mortality of three common Caribbean reef corals. Coral Reefs 12:143-152

Caswell H (2001) Matrix population models. Sinauer Associates, MA

Clark JS, Carpenter SR, Barber M, Collins S and others (2001) Ecological forecasts: an emerging imperative. Science 293:657-660

Clark R, Jeffrey C, Woody K, Hillis-Starr Z, Monaco M (2009) Spatial and temporal patterns of coral bleaching around Buck Island Reef National Monument, St. Croix, US Virgin Islands. Bull Mar Sci 84:167-182

> Cole LC (1954) The population consequences of life history phenomena. Q Rev Biol 29:103-137

$>$ Done TJ (1988) Simulation of recovery of pre-disturbance size structure in populations of Porites spp. damaged by the crown of thorns starfish Acanthaster planci. Mar Biol 100: $51-61$

Done TJ (1999) Coral community adaptability to environmental change at the scales of regions, reefs, and reef zones. Am Zool 39:66-79

> Done TJ, Potts DC (1992) Influences of habitat and natural disturbances on contributions of massive Porites corals to reef communities. Mar Biol 114:479-493

Donner SD, Knutson TR, Oppenheimer M (2007) Modelbased assessment of the role of human-induced climate change in the 2005 Caribbean coral bleaching event. Proc Natl Acad Sci USA 104:5483-5488

> Dunstan PK, Johnson CR (1998) Spatio-temporal variation in coral recruitment at different scales on Heron Reef, southern Great Barrier Reef. Coral Reefs 17:71-81

> Edmunds PJ (2000) Patterns in the distribution of juvenile corals and coral reef community structure in St. John, US Virgin Islands. Mar Ecol Prog Ser 202:113-124

Edmunds PJ (2002) Long-term dynamics of coral reefs in St. John, US Virgin Islands. Coral Reefs 21:357-367

Edmunds PJ (2004) Juvenile coral population dynamics track rising seawater temperature on a Caribbean reef. Mar Ecol Prog Ser 269:111-119

Edmunds PJ (2007) Evidence for a decadal-scale decline in the growth rates of juvenile scleractinan corals. Mar Ecol Prog Ser 341:1-13

- Edmunds PJ (2008) The effects of temperature on the growth of juvenile scleractinian corals. Mar Biol 154:153-162

Edmunds PJ, Elahi R (2007) The demographics of a 15-year decline in cover of the Caribbean reef coral Montastraea annularis. Ecol Monogr 77:3-18

Edmunds PJ, Gates RD (2004) Size-dependent differences in the photophysiology of the reef coral Porites astreoides. Biol Bull 206:61-64

Federal Register (2010) Endangered and threatened wildlife; notice of 90-day finding on a petition to list 83 species of corals as Threatened or Endangered under the Endangered Species Act (ESA). Fed Regist 75:6616-6621

> Fitt WK, Brown BE, Warner ME, Dunne RP (2001) Coral bleaching: interpretation of thermal limits and thermal thresholds in tropical corals. Coral Reefs 20:51-65

Fong P, Glynn PW (2000) A regional model to predict coral population dynamics in response to El Niño-Southern Oscillation. Ecol Appl 10:842-854

- Fujiwara M, Caswell H (2001) Demography of the endangered north Atlantic right whale. Nature 414:537-541

Fukami H, Chen CA, Budd AF, Collins A and others (2008) Mitochondrial and nuclear genes suggest that stony corals are monophyletic but most families of stony corals are not (Order Scleractinia, Class Anthozoa, Phylum Cnidaria). PLoS ONE 3(e3222):1-9

Gardner TA, Cote IM, Gill JA, Grant A, Watkinson AT (2003) Long-term, region-wide declines in Caribbean corals. Science 301:958-960

Gardner TA, Coté IM, Gill JA, Grant A, Watkinson AR (2005) Hurricanes and Caribbean coral reefs: impacts, recovery patterns, and role in long-term decline. Ecology 86: $174-184$

> Gleason DF (1993) Differential effects of ultraviolet radiation on green and brown morphs of the Caribbean coral Porites astreoides. Limnol Oceanogr 38:1452-1463

> Glynn PW (1993) Coral reef bleaching: ecological perspectives. Coral Reefs 12:1-17

$>$ Goreau TF (1959) The ecology of Jamaican reefs. I. Species composition and zonation. Ecology 40:67-90

Green DH (2009) Recruitment and early post-settlement success of juvenile corals in St. John, US Virgin Islands. MS 
thesis, California State University, Northridge, CA

Green DH, Edmunds PJ, Carpenter RC (2008) Increasing relative abundance of Porites astreoides on Caribbean reefs mediated by an overall decline in coral cover. Mar Ecol Prog Ser 359:1-10

Green DH, Edmunds PJ, Pochon X, Gates RD (2010) The effects of substratum type on the growth, mortality, and photophysiology of juvenile corals in St. John, US Virgin Islands. J Exp Mar Biol Ecol 384:18-29

Grime JP (1977) Evidence for the existence of three primary strategies in plants and its relevance to ecological and evolutionary theory. Am Nat 111:1169-1194

Hall VR, Hughes TP (1996) Reproductive strategies of modular organisms: comparative studies of reef-building corals. Ecology 77:950-963

> Hoegh-Guldberg O, Mumby PJ, Hooten AJ, Steneck RS and others (2007) Coral reefs under rapid climate change and ocean acidification. Science 318:1737-1742

Hughes TP (1984) Population dynamics based on individual size rather than age: a general model with a reef coral example. Am Nat 123:778-795

Hughes TP, Jackson JBC (1985) Population dynamics and life histories of foliaceous corals. Ecol Monogr 55: 141-166

> Hughes TP, Tanner JE (2000) Recruitment failure, life histories, and long-term decline of Caribbean corals. Ecology 81:2250-2263

Hughes TP, Baird AH, Bellwood DR, Card M and others (2003) Climate change, human impacts, and the resilience of coral reefs. Science 301:929-933

Hunt HL, Scheibling RE (1997) Role of early post-settlement mortality in recruitment of benthic marine invertebrates. Mar Ecol Prog Ser 155:269-301

Huston M (1985) Variation in coral growth rates with depth at Discovery Bay, Jamaica. Coral Reefs 4:19-25

IPCC (Intergovernmental Panel on Climate Change) (2007) Climate change 2007: The physical science basis. Contribution of Working Group I to the fourth assessment report of the Intergovernmental Panel on Climate Change. Cambridge University Press, Cambridge

> Jones AM, Berkelmans R, van Oppen MJH, Mieog JC, Sinclair W (2008) A community change in the algal endosymbionts of a scleractinian coral following a natural bleaching event: field evidence of acclimatization. Proc Biol Sci 275:1359-1365

- Jones GP, Amany GR, Russ GR, Sale PF, Steneck RS, van Oppen MJH, Willis BL (2009) Larval retention and connectivity among populations of corals and reef fishes: history, advances and challenges. Coral Reefs 28: $307-325$

Knowlton N (2001) The future of coral reefs. Proc Natl Acad Sci USA 98:5419-5425

Knowlton N, Jackson JBC (2008) Shifting baselines, local impacts, and global change on coral reefs. PLoS ONE 6: e54

LaJeunesse TC (2002) Diversity and community structure of symbiotic dinoflagellates from Caribbean coral reefs. Mar Biol 141:387-400

Lesser MP (2007) Coral reef bleaching and global climate change: can corals survive the next century? Proc Natl Acad Sci USA 104:5259-5260

Lirman D (2003) A simulation model of the population dynamics of the branching coral Acropora palmata. Ecol Model 161:167-180

Lough JM, Barnes DJ (1997) Several centuries of variation in skeleton extension, density and calcification in massive Porites colonies from the Great Barrier Reef: a proxy for seawater temperature and a background of variability against which to identify unnatural change. J Exp Mar Biol Ecol 211:29-67

Loya Y, Sakai K, Yamazato K, Nakano Y, Sambali H, van Woesik R (2001) Coral bleaching: the winners and losers. Ecol Lett 4:122-131

Malthus TR (1798) An essay on the principles of population, as it affects the future improvement of society with remarks on the speculation of Mr. Godwin, M. Condorcet, and other writers. Johnson J, London

Meesters EH, Hilterman M, Kardinaal E, Keetman M, deVries M, Bak RPM (2001) Colony size-frequency distributions of scleractinian coral populations: spatial and interspecific variation. Mar Ecol Prog Ser 209:43-54

Miller J, Muller E, Rogers C, Waara R and others (2009) Coral disease following massive bleaching in 2005 causes $60 \%$ decline in coral cover on reefs in the US Virgin Islands. Coral Reefs 28:925-937

Mydlarz LD, McGinity ES, Harvell CD (2010) What are the physiological and immunological responses of coral to climate warming and disease? J Exp Biol 213:934-945

Pandolfi JM, Jackson JBC (2006) Ecological existence interrupted in Caribbean coral reefs. Ecol Lett 9:818-826

Pandolfi JM, Jackson JBC, Bradbury RH, Guzman HM and others (2005) Are U.S. coral reefs on the slippery slope to slime? Science 307:1725-1726

> Parmesan C (2006) Ecological and evolutionary responses to recent climate change. Annu Rev Ecol Syst 37:637-669

> Rogers CS, Miller J (2006) Permanent 'phase shifts' or reversible declines in coral cover? Lack of recovery of two coral reefs in St. John, US Virgin Islands. Mar Ecol Prog Ser 306:103-114

Rogers CS, Miller J, Muller EM, Edmunds PJ and others (2008) Ecology of coral reefs in the US Virgin Islands. In: Riegl BM, Dodge RE (eds) Coral Reefs of the World I. Springer, Berlin, p 303-373

Sampayo EM, Ridgway T, Bongaerts P, Hoegh-Guldberg O (2008) Bleaching susceptibility and mortality of corals are determined by fine-scale differences in symbiont type. Proc Natl Acad Sci USA 105:10444-10449

Santangelo G, Bramanti L, Iannelli M (2007) Population dynamics and conservation biology of the over-exploited Mediterranean ref coral. J Theor Biol 244:416-423

Serchuk F, Schmitt CJ, Floyd B (1980) Rainbow trout: a population based on individual responses to varying environmental and demographic parameters. Environ Biol Fishes 5:15-26

Smith SR (1992) Patterns of coral recruitment and postsettlement mortality on Bermuda's reefs: comparison to Caribbean and Pacific reefs. Am Zool 32:663-673

Soong K, Chen CA, Chang JC (1999) A very large poritid colony at Green Island, Taiwan. Coral Reefs 18:42

Stat M, Carter D, Hoegh-Guldberg O (2006) The evolutionary history of Symbiodinium and scleractinian hosts - symbiosis, diversity, and the effect of climate change. Perspect Plant Ecol Evol Syst 8:23-43

Szmant A (1986) Reproductive ecology of Caribbean reef corals. Coral Reefs 5:43-54

Tanner JE, Hughes TP, Connell JH (2009) Community-level density dependence: an example from a shallow coral assemblage. Ecology 90:506-516

Tomascik T, Sander F (1987) Effects of eutrophication on reefbuilding corals II. Structure of scleractinian coral communities on fringing reefs, Barbados, West Indies. Mar Biol 94:53-75

Treml E, Colgan M, Keevican M (1997) Hurricane disturbance and coral reef development: a geographic informa- 
tion system (GIS) analysis of 501 years of hurricane data from the Lesser Antilles. Proc 8th Int Coral Reef Symp 1: 541-546

Vandermeer J (1978) Choosing category size in a stage projection matrix. Oecologia 32:79-84

- Vermeij MJA, Sandin SA (2008) Density-dependent settlement and mortality structure the earliest life phases of a coral population. Ecology 89:1994-2004

Veron JEN (2000) Corals of the world. Australian Institute of

Editorial responsibility: Charles Birkeland,

Honolulu, Hawaii, USA
Marine Science, Townsville

Wilkinson C, Souter D (2008) Status of Caribbean coral reefs after bleaching and hurricanes in 2005. Global Coral Reef Monitoring Network, and Reef and Rainforest Research Centre, Townsville

Wittenberg M, Hunte W (1992) Effects of eutrophication and sedimentation on juvenile corals I. Abundance, mortality and community structure. Mar Biol 112:131-138

Zar JH (1999) Biostatistical analysis. Prentice Hall, NJ

Submitted: December 30, 2009; Accepted: September 8, 2010

Proofs received from author(s): November 4, 2010 